\title{
4-Hydroxyproline Containing Podands: New Chiral Catalysts of the Asymmetric Biginelli Reaction ${ }^{+}$
}

\author{
Yulia Titova *, Irina Ovchinnikova, Olga Fedorova, Gennady Rusinov and Valery Charushin \\ Postovsky Institute of Organic Synthesis, Russian Academy of Sciences (Ural Branch), 620990 Ekaterinburg, \\ Russia; iov@ios.uran.ru (I.O.); fedorova@ios.uran.ru (O.F.); rusinov@ios.uran.ru (G.R.); \\ charushin@ios.uran.ru (V.C.) \\ * Correspondence: titova@ios.uran.ru \\ + Presented at Symmetry 2017-The First International Conference on Symmetry, Barcelona, Spain, 16-18 \\ October 2017.
}

Published: 4 January 2018

4-Aryl substituted dihydropyrimidines (DHPMs), the products of the multicomponent Biginelli reaction, are well known as cardiotropic, hypotensive, antitumor, anti-inflammatory, antifungal and antiviral agents. Considerable attention is paid to their asymmetric synthesis due to the fact that the pharmacological activity of enantiomers of chiral DHPMs can vary considerably.

Previously, we showed the prospects of using proline derivatives as chiral catalysts in the asymmetric Biginelli reaction [1,2].

Herein, we report the synthesis of new C2-symmetric chiral catalysts based on acyclic analogs of crown-ether (podands) and 4-hydroxyproline.

The combination of the S-shaped conformation of the polyester chain with the optically active centers of the proline fragment in C2-symmetric organocatalysts made it possible to obtain the product of the Biginelli reaction with $68-72 \% e e$.

Acknowledgments: The work was financially supported by the Russian Science Foundation (project no. 15-1300077 in the part of studying the asymmetric Biginelli reaction) and the Russian Foundation for Basic Research (project no. 16-29-10757-ofi_m in the part of synthesis of chiral catalysts).

\section{References}

1. Fedorova, O.V.; Titova, Y.A.; Vigorov, A.Y.; Toporova, M.S.; Alisienok, O.A.; Murashkevich, A.N.; Krasnov, V.P.; Rusinov, G.L.; Charushin, V.N. Asymmetric Biginelli Reaction Catalyzed by Silicon, Titanium and Aluminum Oxides. Catal. Lett. 2016, 146, 493-498.

2. Titova, Y.; Fedorova, O.; Rusinov, G.; Vigorov, A.; Krasnov, V.; Murashkevich, A.; Charushin, V. Effect of nanosized $\mathrm{TiO}_{2}-\mathrm{SiO}_{2}$ covalently modified by chiral molecules on the asymmetric Biginelli reaction. Catal. Today 2015, 241, 270-274.

() 2018 by the authors. Licensee MDPI, Basel, Switzerland. This article is an open access article distributed under the terms and conditions of the Creative Commons Attribution (CC BY) license (http://creativecommons.org/licenses/by/4.0/). 